\title{
Consideraciones del bioderecho sobre la eutanasia en Colombia*
}

\section{Considerations of bio-law on euthanasia in Colombia}

\section{Considerações do Bio-direito sobre a eutanásia na Colômbia}

Fecha de recepción: 10 de agosto de 2016

Fecha de evaluación: 9 de noviembre de 2016

Fecha de aceptación: 30 de noviembre de 2016

Disponible en línea: 5 de diciembre de 2016

José Antonio García Pereáñez

DoI: http://dx.doi.org/10.18359/rlbi.2637

Como citar:

García Pereáñez, J. (2016). Consideraciones del bioderecho sobre la eutanasia en Colombia. Revista Latinoamericana de Bioética, 17(1), 200-221. DoI: http://dx.doi.org/10.18359/rlbi.2637

\footnotetext{
Artículo de reflexión.

** Doctor en Bioética, Magíster en Derecho, Comunicaciones y Filosofía. Docente Investigador de la Corporación Universitaria Americana, Medellín. Profesor de la Universidad de Antioquia. Correo electrónico: jgarciap@coruniamericana.edu.co / jantonio.garcia@udea.edu.co. ORCID: http://orcid.org/0000-0002-9078-1511. Medellín, Colombia.
} 


\title{
Resumen
}

Este artículo aborda de manera reflexiva las incidencias del bioderecho sobre situaciones de eutanasia en Colombia, al interpretar conflictos morales y jurídicos suscitados por las sentencias de la Corte Constitucional C239 de 1997, T970 de 2014 y la Resolución del Ministerio de Salud y Protección Social 1216, de 2015. El propósito fundamental es el análisis de las decisiones judiciales sobre el final de la vida humana. Por lo tanto, se realiza una revisión de la construcción histórica y jurídica del concepto de eutanasia y se propone la discusión sobre su manejo jurídico y su influencia en el colectivo moral. Asimismo, se diserta sobre el concepto de dignidad humana y muerte digna, como precedentes para dirimir los conflictos éticos que la eutanasia suscita. Al final, se analiza el caso de don Ovidio González, quien se convirtió en 2015 en el primer colombiano en recibir la eutanasia de manera legal dentro del sistema de salud.

Palabras clave: bioderecho, eutanasia, dignidad humana, muerte digna, conflictos morales.

\begin{abstract}
This paper reflectively addresses the incidence of bio-law on euthanasia situations in Colombia by interpreting moral and legal disputes arising from the sentences of the Constitutional Court C239 of 1997, T970 of 2014 , and Resolution 1216 of the Ministry of Health and Social Protection of 2015. The main purpose is the analysis of judicial decisions regarding the end of human life. A review of the historical and legal construction of the euthanasia concept is done, and a discussion of its legal management and its influence on the moral collective is proposed. The concept of human dignity and dignified death are discussed to solve the ethical conflicts that euthanasia causes. Finally, the case of Ovidio González is analyzed; Mr Gonzalez became the first Colombian to receive euthanasia in a legal way within the health system in 2015.
\end{abstract}

Keywords: Bio-law, euthanasia, human dignity, dignified death, ethical conflicts.

\section{Resumo}

Este artigo aborda de maneira reflexiva as incidências do Biodireito sobre situações de eutanásia na Colômbia, ao interpretar as disputas morais e legais decorrentes das decisões da Corte Constitucional C239 de 1997 T970 de 2014 e a Resolução do Ministério da Saúde e Proteção Social 1216, de 2015. O objetivo principal é a análise das decisões judiciais sobre o fim da vida humana. Portanto, realiza-se uma revisão da construção histórica e jurídica do conceito de eutanásia e propõe-se a discussão de sua administração legal e sua influência sobre o coletivo moral. Igualmente, expõe-se sobre o conceito de dignidade humana e morte digna, como precedentes para resolver os conflitos éticos que a eutanásia suscita. No final, e analisado o caso de Dom Ovidio González, que em 2015 se tornou o primeiro colombiano a receber a eutanásia legalmente no interior do sistema de saúde.

Palavras-chave: Biodireito, eutanásia, dignidade humana, morte digna, conflitos morais. 


\section{Introducción}

El bioderecho es una disciplina emergente de la bioética que, en las dos últimas décadas ha pretendido afrontar soluciones a conflictos morales en el marco del derecho, con una fuerte incidencia en los derechos humanos. El auge de la biotecnología ha marcado una ocurrencia sin precedentes en la vida humana, con repercusiones directas en la sociedad y en la persona. El impacto de la investigación con seres humanos ha producido cambios rotundos en la cotidianidad, al suscitar escepticismos éticos; por esto, para garantizar el mantenimiento de la dignidad como principio fundamental de los derechos humanos, se hace necesaria la intervención jurídica.

El bioderecho propone límites jurídicos a la influencia de la ciencia y la tecnología en la intimidad humana, al dirimir el conflicto entre lo natural y lo artificial, proponiendo ajustes coercitivos desde la ley a situaciones que no se resuelven con códigos de honor, como la relatividad creciente sobre el comienzo y final de la vida, la toma de decisiones y la prevalencia de la autonomía de la persona, en contraste con los avances de la medicina. Esto obliga a tomar medidas para mantener la garantía por el derecho a la intimidad de los ciudadanos, la salvaguardia de lo cultural y lo multicultural, la defensa del ambiente como propiedad de responsabilidad ciudadana y el mantenimiento del Estado social como garante del bienestar de la ciudadanía.
Las preocupaciones y reflexiones interdisciplinarias de la bioética dieron origen al bioderecho. La bioética, primero como neologismo y luego como disciplina académica, tuvo su origen en la década de los setenta, cuando estableció relaciones entre las ciencias que procuran el mantenimiento de la vida y la ética, mediante los enfoques principialista, crítico y personalista. Potter (s. f), oncólogo de la Universidad de Wisconsin, Estados Unidos, se planteó la bioética como un nexo entre las culturas científica y humanista. Su pretensión mayor fue la aplicación del saber biológico para el mejoramiento de la calidad de vida. Con todo, el entorno conceptual que abarca la bioética como disciplina académica no está del todo delimitada y su definición en sí misma es muy amplia. Y aunque el cultivo de la disciplina bioética es reciente, no lo son así los problemas de los que se ocupa, ni sus principios e interrogantes, pues configura su actuar como una ética aplicada.

El bioderecho guarda afinidad con la bioética. Se trata pues del estudio del aspecto jurídico de las mismas temáticas que esa disciplina aborda: el comienzo y final de la vida; la garantía de la dignidad humana frente a los avances biotecnológicos y los límites entre la procreación natural y artificial, entre otros. El bioderecho se ocupa de proponer posturas objetivistas a los problemas, al superar el estado de opinión, de valoración individual que relativiza las posiciones, las cuales tienen mayor expresión, si se 
determinan en un escenario de justicia consensual, solidaria e integral. Por esto, el abordaje biojurídico de los temas de los cuales se ocupa la bioética es de gran importancia y necesidad.

Algunos teóricos contemporáneos, entre ellos (Atienza, 1999), proponen la juridificación de la bioética, esto entendido no como una sanción al incumplimiento de los procedimientos éticos, sino como un asunto de conexión entre el derecho y la bioética de tipo metodológico, lo que identifica el conflicto jurídico, al resolverlo con la "ponderación de principios contrapuestos". Ese curso de acción se propone en este artículo con el fin de reflexionar sobre la despenalización de la eutanasia en Colombia, por considerar el equilibrio deliberativo para dirimir las distancias conceptuales en abierta oposición, las mismas que han polarizado la opinión pública.

Lo anterior es el contexto para la pregunta que orienta este escrito: ¿en qué medida es justo poner fin a la vida de un enfermo terminal que padece intensos dolores o de un paciente en estado vegetativo persistente, o de un anciano "interdicto" declarado incapaz para consentir?

De este modo, se propone la discusión sobre la eutanasia en Colombia en dos aspectos centrales que la controvierten: la revisión histórico-jurídica de su concepto y la dimensión actual de los conflictos morales y jurídicos que la involucran, como la significación de la dignidad humana y la caracterización de la muerte digna. Con este fin se analiza el caso de don Ovidio González (Salud, 2015), quien se convirtió en el primer colombiano en recibir la eutanasia de forma legal en el país. Su situación dejó en evidencia que la discusión sobre la eutanasia es un asunto no solo para argumentaciones de tipo moral, sino también para enfrentar deliberaciones legales, sugeridas por el bioderecho.

\section{La eutanasia, revisión del concepto}

Para efectos de la revisión del concepto de eutanasia, se hace especial referencia a la historiografía planteada por Humphry y Wickett, (1990). Nominalmente, se compone el término eutanasia de dos raíces griegas eu y thanatos, que significan "bueno" y "muerte". La referencia grecorromana más antigua sugiere con ello una muerte tranquila, sin ningún dolor. Se decía en aquel entonces que era la invocación preferente del emperador César Augusto; es decir, acerca de una "muerte dulce e indolora", para él y su familia.

Gracia (1990) en "Historia de la eutanasia" hace alusión a esta práctica, al remontarse a los pueblos primitivos de la prehistoria, que permitían a sus congéneres "dejar morir" a incapaces, inválidos, ancianos o enfermos incurables. El autor también referencia lo que él denomina la medicalización de la eutanasia en la antigüedad, cuando 
los griegos dejaron este encargo en los médicos, sucesores de la tradición hipocrática, quienes "juraban" nunca ofrecer a los pacientes fármacos letales, a pesar de que ellos mismos los solicitaran con vehemencia, a causa de sus intensos dolores y múltiples padecimientos.

Con el trasegar histórico de la Edad Media y la cristianización de Occidente, imperó la idea de la sacralización del cuerpo y con ello el dolor humano se interpretó como fuente de santificación. Por esto, se condenaron las prácticas del suicidio y la eutanasia, posturas que refrendó el escolasticismo de la época, al trasmitirlas en su acción educativa y evangelizadora, con y así se alcanzó a justificar la gesta de la colonización de las américas, incluso más allá de los siglos xv y xvI, como advierten Humphry y Wickett (1995).

El Renacimiento recuperó las ideas griegas y romanas del pensamiento antiguo, en una corriente que tuvo su epicentro sobre todo en Francia e Italia, donde se dieron las condiciones por medio de la expresión artística, para volver a pensar la muerte como un episodio fácil y agradable en medio de las penurias de la vida. De este modo, se preparó el escenario ideológico para que la propuesta de Francis Bacon, según Reich (1995), de reactualizar la eutanasia como un "auxilio benéfico" fuera replicada por los médicos y la pudieran ofrecer a sus pacientes, como una solución en medio del dolor y la calamidad de una enfermedad incurable. Sobre este particular, también Gracia (1990) hace un breve comentario a la obra de Bacon, titulada El avance de la ciencia. El autor propone una ligera semblanza de la eutanasia externa y la identifica como una ayuda del médico para acelerar la muerte del enfermo, por considerarla una acción benigna.

Por otro lado, famosa fue la obra de Marx (1977), publicada en 1826 y titulada Medical Euthanasia. Se trataba de todo un manual de educación médica para enseñar el cuidado de los enfermos que están más cerca de la muerte. Así también, se editó con éxito la obra del doctor Humphry (Humphry y Wickett, 1989), que impartía directrices a los médicos, para atender a los pacientes terminales y ayudarles a poner fin a su sufrimiento.

En la primera mitad del siglo $\mathrm{xx}$, los intentos por solicitar democráticamente el derecho a una muerte digna se vieron entorpecidos por el genocidio nazi, obnubilado por su abierta pretensión eutanásica. Después de 1950, se presentó un acelerado progreso biotecnológico, lo que suscitó cambios apreciables en la atención médico-paciente, en especial con la consideración del "enfermo terminal" y la responsabilidad médica sobre su estado. Esto, sumado al incremento de enfermedades graves con desenlace dramático, como el cáncer, el sida y el mal de Alzheimer, entre otros que, aun presentando un deterioro progresivo e irreversible en la persona que los padecen, hacen que el final de la vida se torna lento y doloroso. 
Por tanto, la revisión histórica del concepto de eutanasia presenta variables en el tiempo; las primeras, del lado de un recto raciocinio y una lógica entre la vida y la muerte; las siguientes, mediadas por una moral que deviene de credos religiosos, en contraste con la invocación del derecho a la autonomía, propio de las democracias modernas. Con todo, y en este tiempo, los adelantos biotecnológicos y la globalización de las comunicaciones sugieren un debate respetuoso sobre el tema, pretendiendo consensos y respetando disensos.

El significado del concepto de eutanasia ha variado en la historia, pero en lo que compete a la época actual es importante considerar la reflexión de Reich (1995), mencionada por The Encyclopedia of bioethics, de 1995 , que propone cuatro significados para la eutanasia: 1) inducir la muerte a quienes están sufriendo; 2) terminar con la vida de quienes son indeseables; 3) dar atención a los moribundos, y 4) dejar morir a los enfermos terminales. Estos son significados de eutanasia que no pueden considerarse por separado, sino en su conjunto; además, porque es decisivo e imperante determinar la moralidad de cada uno de ellos. El primero, "inducir a la muerte a quien está sufriendo", puede comprenderse en un contexto de solidaridad y compasión, aunque no es claro en quién recae la decisión; el segundo, "terminar con la vida de indeseables", es una abierta injusticia mediada por la segregación y la discriminación; el tercero, "dar atención a los moribundos", es impreciso, pues no se refiere a qué clase de atención habría que brindarle; y el cuarto, "dejar morir a los enfermos terminales", puede interpretarse, en nuestro contexto, como una omisión del ejercicio médico asistencial, aunque en Colombia existe una ley para los cuidados paliativos en enfermos terminales, a pesar de las dificultades crecientes con los servicios médicos asistenciales.

Por otro lado, revisando un texto dedicado al tema de la muerte digna en Encyclopedia of Death, el doctor Richman (1993) se comprometió con el significado etimológico de eutanasia y la definió como "una buena muerte, tranquila y sin dolor" (p. 273). Con esto, abona a la polémica, pues la disputa para él se presenta en cómo se realiza y no en el qué es la eutanasia. Richman es enfático al afirmar que la discusión sobre la moralidad y legalidad de la práctica de la eutanasia compromete el ejercicio médico; por esto, propone el debate en el contexto del acto médico asistencial.

En la actual discusión sobre la valoración moral de la eutanasia en Colombia, intervienen en juristas y teólogos, especialmente, los cuales polarizan a la población en este debate. Pero son los médicos los que deben tomar parte activa, al sugerir una deliberación humanística y científica sobre el tema. Por esto, es muy bien vista la determinación de la Corte Constitucional al exigirle al Ministerio de Salud y Protección Social 
que proponga la reglamentación de la eutanasia en Colombia, ante el silencio de omisión y oprobio del Congreso de la República que, después de 18 años de despenalizada la eutanasia, de forma negligente se ha negado protocolizar la ley que la dispone. Resultado de esto es la Resolución 1216 del 20 de abril de 2015, por medio de la cual el Gobierno da cumplimiento a la orden cuarta de la Sentencia T970, de 2014, en relación con las directrices para la organización y funcionamiento de los comités hospitalarios, para hacer efectivo el derecho a morir de manera digna. A pesar de esto, en la citada resolución el término eutanasia es ambiguo y confuso, y se presenta como un obstáculo epistemológico para efectos de discutir su conveniencia.

En una búsqueda de mayor precisión para el concepto de eutanasia, los doctores Overbeke y Hart Wimpert (citados en Look, Last y Dunea, 2001), definen esta última como "la terminación intencional de la vida o la interrupción intencional de los procedimientos destinados a prolongar la vida, por un médico" (p. 153). En esta definición, los autores excluyen a incapaces e interdictos. El carácter intencional recae en el médico y excluye a adultos mentalmente incompetentes, pues ha de entenderse su acción como respuesta a la determinación del paciente.

El doctor Have (1996), en la Declaración de Eutanasia en Holanda, define esta práctica así: "es la finalización intencional, por parte de un médico, de la vida de un paciente, a petición de este" (p. 44). Son de primordial importancia, según este autor, la intención del médico de ayudar a su paciente a terminar con su sufrimiento, así como la petición del paciente, autónoma y persistente, y el mismo médico, quien realiza la eutanasia. Sin estos elementos primordiales, Have declara que el procedimiento deja de ser eutanásico para convertirse en un homicidio.

Con todo, y para concluir con la revisión histórica y conceptual de la eutanasia, el acápite final lo propone The World Medical Association (WMA) (2016), al calificar la eutanasia como una práctica inmoral que atenta contra la "ética médica" y la define en Declaration on eutanasia como "el acto de terminar deliberadamente con la vida de un paciente, incluso ante la petición de este" (p. 1).

\section{La eutanasia, según el bioderecho en Colombia}

La Corte Constitucional (1997), mediante la Sentencia C-239, determinó estar ajustado a la Constitución el artículo 326 del Código Penal, que identifica el delito de eutanasia bajo la condición de que el paciente lo haya expresado de manera libre, mediante consentimiento informado. De esto no podrá derivarse responsabilidad penal para el médico, que lleva a efecto la asistencia eutanásica.

En la Corte Constitucional (1997), en la Sentencia C-239, el magistrado Vladimiro Naranjo Mesa expres, que 
la eutanasia se refiere justamente a la conducta que describe el artículo 326, del Código Penal. En primer lugar, hace unas precisiones terminológicas entre eutanasia activa y pasiva; es decir, distanasia y medicina paliativa. Luego, explica el sustento de ilegitimidad jurídica de la conducta eutanásica que, para este análisis, se identifica en los principios bioéticos. Sobre la autonomía, lo hace a partir de la concepción personalista del derecho a la vida, que parte del derecho como tal, en cuanto para el viviente la vida es su mismo ser. Según Naranjo, ser y vivir se identifica de forma mutua. Para determinar el alcance y los límites del derecho a la vida, se hace necesario identificar lo que el ser humano es, desde este punto de vista y a diferencia de los demás seres vivientes, un ser personal que se domina así mismo por la razón y este dominio lo expresa en la libertad.

Sin embargo, el dominio sobre sí mismo no es absoluto, pues carece de un control ontológico sobre su existencia. Por ello, la libertad humana y, en específico, el derecho al libre desarrollo de la personalidad, no son absolutos y, por ende, no sirven de fundamento para legitimar la disposición sobre la propia vida, pues la naturaleza humana no comporta ese dominio ontológico sobre el propio ser. En ese sentido, se considera la vida como un derecho irrenunciable, carácter que, por demás, tiene todos los derechos fundamentales.

Propone el magistrado Naranjo el principio de beneficencia, al criticar el modelo de virtud que viene invocando la Corte Constitucional pues, según la Constitución que nos rige, se sugiere un modelo de virtud del cual no resulta legítimo imponer una concepción específica de la moral y, de acuerdo con el interés jurídicamente protegido, no puede ser la honestidad ni la moral, ya que cada persona tiene, en ese terreno, derecho a conducir su vida por sus propias decisiones. Esto constituye, para Naranjo, una posición inaceptable, debido a que la (Corte Constitucional, 1994) en la Sentencia C-224, con ponencia del magistrado Jorge Arango Mejía, la Corte admitió que la Constitución Nacional reconoce validez jurídica a las normas morales y al concepto de moralidad y que, por lo tanto, resulta válido que las normas tengan en cuenta la moral vigente para deducir consecuencias jurídicas. Esa sentencia reconoce que en todas las comunidades existe una moral social que prevalece en cada pueblo, en su propia circunstancia y, en ese sentido, la moral cristiana es la que se mantiene aún en la sociedad colombiana. La sentencia a la que se refiere el doctor Naranjo declaró exequible el artículo 13, de la Ley 153 de 1887, entendiéndose que la expresión moral cristiana significa "moral social".

Para el magistrado Naranjo, el fallo del cual se aparta desconoce esa moral general del pueblo colombiano y ese mínimo ético de beneficencia. La Sentencia C-239 se edifica, según él, en un pretendido derecho a la muerte que simplemente no existe, porque tal 
posibilidad desconocería el principio lógico de no contradicción. En efecto, si para el viviente, ser y vivir son lo mismo, el derecho a SER; esto es, el derecho a la vida, no puede coexistir con el derecho a no ser; o sea, el derecho a la muerte.

Con todo, la disposición constitucional de proteger la autonomía de cada individuo y, con ello, el libre desarrollo de la personalidad, fundamentan un marco jurídico mediante el cual nadie podría ser obligado a vivir en condiciones indignas si se siente agobiado y desahuciado por situaciones propias de una enfermedad terminal, con la cual el estado de la salud empeoraría de forma indefectible.

El punto más alto de este debate lo propuso el doctor Carlos Gaviria Díaz, con los textos que escribió para justificar desde el ámbito filosófico la eutanasia y el suicidio asistido, con la misma Sentencia C-239 de la cual fue proponente en 1997. Su ascendente fue más liberal que quienes revisaron la sentencia y más que el ciudadano que la Constitución dice proteger. El doctor Gaviria expresa que la Carta Magna colombiana goza de todo el andamiaje jurídico para proteger la autonomía de quien siente que su dignidad está desmejorada y amenazada ante una enfermedad inminente, con secuelas y visos de ignominia.

No parece pues ser un argumento de peso contundente, el esgrimir como cierto y aplicable el primer artículo de la Constitución Nacional, que declara que la nación no solo es pluralista, sino que además protege la dignidad humana. De igual manera ocurre con el libre desarrollo de la personalidad, contenido en el artículo 16; sin embargo, si el ciudadano es autónomo y se le respeta su "libre desarrollo de la personalidad" tendría todos los argumentos a favor para elegir libre y de forma soberana los valores y principios que rigen su conducta. No es admisible que el Estado colombiano, de garante liberal, propenda a la protección del ciudadano desde una visión de cuño paternalista. Por esto, la reflexión de Gaviria Díaz es más contundente.

Ahora bien, si es que, como algunos alegan, el Estado colombiano está en favor de la vida — como sin duda lo está-, la valora como un bien y, en consecuencia, está siempre obligado a protegerla, debe responderse que un bien no puede seguir siéndolo cuando el sujeto moral — su titular- ya no lo valora de ese modo. Solo un estado paternalista —y Colombia, por fortuna, no lo es- puede pretender sustituir a la persona en una decisión radical que solo a ella incumbe. Quien, en esas circunstancias, de manera benévola, accede a poner término a los sufrimientos y a la vida de quien ya no los juzga soportables, no ha suprimido bien alguno. $\mathrm{Ha}$ removido sí una situación miserable, mediante un acto que tiene todo el sello de la benevolencia, de solidaridad y el altruismo.

Con todo, la Corte no analizó lo debido en la pretensión de identificar en el tema de la eutanasia el "derecho 
a una muerte digna". Logró declarar exequible, es decir, constitucional, el homicidio por piedad, pero al tiempo creó una excepción en el caso de que se den dos condiciones: si existe el "consentimiento informado" del sujeto pasivo de la práctica eutanásica y si se cuenta con la presencia de un profesional de la medicina, que prepare todo lo relacionado con la muerte del paciente, respaldado por el consentimiento. Así, el médico estaría exento de responsabilidad penal y, con ello, la Corte autorizó una causal de justificación frente a la eutanasia.

El Estado colombiano está obligado a proteger la vida, pero esta función está totalmente adherida al respeto a la dignidad humana, la autonomía personal, el libre desarrollo de la personalidad y la prohibición de tratos crueles e inhumanos, de cara a los derechos inalienables de la persona, protegidos por la Constitución Política de Colombia. Lo anterior adquiere una importancia capital cuando estos derechos son invocados por un ciudadano que padece un estado de salud irreversible.

Frente a este hecho, la misma Corte señala:

La decisión de cómo enfrentar la muerte adquiere una importancia decisiva para el enfermo terminal, que sabe que no puede ser curado y que, por ende, no está optando entre la muerte y muchos años de vida plena, sino entre morir en condiciones que él escoge o morir poco tiempo después en circunstancias dolorosas y que juzga indignas. El derecho fundamental a vivir en forma digna implica, entonces, el derecho a morir dignamente. (p. 17)

Estos elementos le sirven a la Corte para darle una relevancia especial al consentimiento del sujeto pasivo y así justificar su decisión.

De la Corte Constitucional (1997) en la Sentencia C-239 y del salvamento de voto de algunos magistrados, se pueden extraer consideraciones de la Corte para despenalizar la eutanasia en Colombia. En primer lugar, los magistrados que salvaron su voto son recurrentes en afirmar que el fallo relativizó el derecho a la vida, que pasó de ser un derecho inviolable y fundamental, a un derecho de carácter renunciable y disponible. Lo cierto es que en la argumentación expuesta por la Corte no se infiere que el derecho a la vida pierda sus características ontológicas; al contrario, logra una ponderación concreta y particular de principios, máxime si la referencia es a derechos fundamentales y no a "deberes absolutos", pues estos últimos solo son posibles en legislaciones autoritarias.

La Corte Constitucional (1997), en la Sentencia C-239, expresa una restricción en dos aspectos: solo incluye a enfermos terminales y excluye otras enfermedades que han sido consideras por la Organización Mundial de la Salud (oms) como "catastróficas", en las cuales se evidencian graves padecimientos e intensos dolores, 
como los enfermos con parálisis y cuadriplejias o desfigurados con perfiles de monstruosidad. La Corte solo valida al médico para realizar el análisis del consentimiento informado y deja de lado a otros profesionales del área de la salud e incluso a los jueces. Lo cierto es que estas restricciones no están debidamente justificadas y argumentadas en el texto de la Sentencia.

Si bien es cierto que la sentencia en mención es un avance en la protección de derechos fundamentales, puesto que propone las tesis para la aplicación de la eutanasia activa consentida, también es cierto que abre la discusión para un debate político en el establecimiento de las regulaciones especiales, y en tal caso también de la eutanasia pasiva, distanasia, medicina paliativa y de todos los temas que se relacionen con la muerte digna. De igual manera, a la fecha y con casi 18 años de mora, aún se encuentra sin una respuesta concreta, por medio de una ley de la República, la regulación de la eutanasia en el ordenamiento jurídico colombiano.

\section{Discusión}

La eutanasia ha sido el tema de debate del bioderecho en Colombia, por medio de la Sentencia T-970 de 2014, sin olvidar el antecedente de la Sentencia C-239 de 1997, ambas de la Corte Constitucional y de la reciente Resolución 1216 del 20 de abril de 2015, expedida por el Ministerio de Salud y Protección Social, por medio de la cual se da cumplimiento a lo ordenado por la Corte, en relación con las directrices para la organización y funcionamiento de los comités y el estudio de solicitudes, al invocar el derecho a morir con dignidad.

Siendo esto así, es pertinente precisar algunas cuestiones que proporcionan elementos para la controversia sobre bioderecho en el final de la vida, y es importante analizar los argumentos que esgrimen tanto los promotores de la práctica de la eutanasia, como sus detractores.

En palabras del profesor Herránz (1990), en su publicación "Eutanasia o medicina", la eutanasia es matar sin dolor y de manera deliberada, por medio de procedimientos de apariencia médica, a personas que tienen como destino una vida atormentada por el dolor o limitada por la incapacidad, con el propósito de ahorrarles sufrimiento o de librar a la sociedad de una carga inútil. Por tanto, eutanasia siempre es igual a matar, de ahí deviene la clasificación de la eutanasia, activa o pasiva, y que carezca de validez real, salvo que exista menor valor ético en el que la realice.

Es diferente la eutanasia al suicidio asistido, el cual consiste en morir con la ayuda de otro, pues el paciente no puede hacerlo por sus limitaciones físicas o psicológicas. La distanasia, también conocida como encarnizamiento terapéutico, es lo contrario a la eutanasia y consiste en retrasar el advenimiento de la muerte todo lo posible, por todos los medios proporcionados, aunque no 
haya esperanza alguna de curación y aunque eso signifique exigir al moribundo unos sufrimientos añadidos a los que ya padece y que, obviamente, no lograra esquivar la muerte inevitable, sino solo aplazarla unas horas o unos días en condiciones lamentables. La distanasia es un error ético y una falta de competencia, sostiene el profesor Herránz.

Contrario a lo anterior, la ortotanasia es la defensa del derecho a morir con dignidad, sin el empleo de medios extraordinarios y desproporcionados para el mantenimiento de la vida. Es aceptar el momento de la muerte, en el que tenga que llegar; en estos casos, al enfermo terminal solo se le aplican medidas paliativas: hidratar adecuadamente, suministrar el oxígeno, controlar el dolor, entre otros, lo que permite vivir de forma digna la evolución natural de su enfermedad y que concluye con la muerte natural. No se pretende la provocación de la muerte ni la prolongación de la vida, solo se acepta la muerte sin prolongarla.

La Ley 1733 de 2014 regula los cuidados paliativos en Colombia, para el manejo integral de pacientes con enfermedades terminales, crónicas, degenerativas o irreversibles. Estos procedimientos son considerados cuidados de alto impacto en la calidad de vida de los enfermos y sus familias. De forma curiosa, esta ley no ha sido reglamentada, lo que llama la atención, si se compara con la rapidez y la poca reflexión que se tuvo con la reglamentación de los comités que es- tudian la autorización para la práctica de la eutanasia.

En la actualidad, la eutanasia solo cuenta con autorización jurídica en Holanda, Bélgica, Luxemburgo y Colombia. La Ley que reglamenta la eutanasia en unos sectores en el norte de Australia fue rechazada por la Corte Suprema de ese país y, por ende, ha estado fuera de su ordenamiento jurídico, pues la consideraron como un atentado con alevosía en contra de la dignidad humana. El suicidio asistido está permitido en Suiza y en cuatro estados de Estados Unidos.

En este tiempo, son muchos los argumentos que se debaten a favor y en contra de la eutanasia, de tal manera que en este escrito solo se hará referencia a algunos de ellos. Quienes están a favor de la reglamentación jurídica de la eutanasia sostienen que es necesaria para declinar el dolor de una enfermedad sin salida, que alivia el desgaste físico y emocional que sufren el paciente y sus familiares, al enfrentar una muerte lenta, forzosa y sensiblemente lapidaria, y que esto permitiría acabar con su práctica clandestina, pues cada quien es dueño de su vida y, por ello, cada quien podría decidir cómo dejar de tenerla y elegir cómo quiere morir, haciendo valer su derecho a la autonomía y a su propia libertad.

Los defensores de la reglamentación de la práctica de la eutanasia manifiestan la imperiosa necesidad de separarse de principios religiosos que niegan esta 
práctica, al denominarla como inmoral. Sostienen que existe "un costo médico considerablemente alto, al sostener en el tiempo con vida a un paciente sin ningún pronóstico para recuperar su salud". Esto último era la parte final del tercer requisito que se exigía en el artículo 5 del proyecto de Ley de Eutanasia en Colombia, presentado ante el Congreso de la República, en 2012, por el senador Armando Benedetti (Redacción Política, 2014).

Una de las argumentaciones fuertes en favor de reglamentación de la eutanasia y el suicidio asistido, según Nombela et al. (s. f), es que en el sentido estricto determinadas vidas no generan un derecho a vivirlas o que no existe obligación de mantenerlas; además de que no representan utilidad económica $y$, por el contrario, generan grandes costos al sistema sanitario de los países. De manera que, independiente de que sea autorizada la reglamentación de la eutanasia jurídicamente o no, esta será el reflejo de lo que cada individuo, paciente, médico y la sociedad en general, asuma frente al final de la vida.

Los argumentos en contra de la eutanasia sostienen que cuando alguien la solicita, lo hace no porque quiera morir, sino porque quiere dejar de sufrir. De acuerdo con esta tesis, se dice que dar muerte al enfermo que la pide no significa respetar su derecho a la libertad, sino que significa, en muchos casos, un gran desconocimiento de las diferentes fases que puede pasar un enfermo desahuciado: rebelión, desesperanza, resignación. La eutanasia es innecesaria cuando se cuenta con cuidados paliativos. Las demandas para la eutanasia están mediadas por una gran frustración de los enfermos en fase terminal y la elevada de cuadros crónicos, que nunca son diagnosticados ni tratados.

Situaciones como la de un enfermo en estado terminal, con las circunstancias que lo rodean: una atención deficiente de sus necesidades, la sensación de inutilidad y de ser una carga, el miedo al dolor y al deterioro físico, pueden estar condicionando, de forma seria, su libertad y presentándole el suicidio asistido o la eutanasia como la única escapatoria a una situación que le resulta o se imagina a futuro como insoportable.

La eutanasia desalienta la investigación médica, cambia la conciencia pública, viola los códigos históricamente aceptados de ética médica. La vida del más débil queda en las manos del más fuerte. Con esto, se pierde el sentido de justicia, de reciprocidad y de confianza en la sociedad. Un colectivo social y democrático no puede encargarse del asesinato organizado de los ciudadanos. Permitir la eutanasia pone en peligro la vida de los vulnerables, corrompe la práctica médica y pone en riesgo la institución familiar y el compromiso generacional por el mantenimiento de la dignidad humana y de la igualdad de los ciudadanos. 


\section{La muerte digna y dignidad humana}

Conviene ahora detenerse para ahondar en los principios de la dignidad humana y desde ellos interpretar el concepto de muerte digna. La Corte Constitucional Colombiana, en su constructo interpretativo, ha identificado la dignidad humana como principio, derecho, fundamento, valor, presupuesto, fin en sí mismo; bien jurídico supremo, atributo de la persona y marco de interpretación. A simple vista se puede inferir que faltaría rigurosidad interpretativa por parte de la Corte, pues tantos términos sobre la dignidad humana han contribuido a una elaboración confusa, ya como derecho, ya como garantía. Esto ha logrado que se convierta en un término vago, impreciso y sin concreción. La falta de criterios estrictos para interpretar la dignidad humana, por parte de la Corte, se observa en los fallos de los jueces y, por tanto, en la opinión pública, pues no existe un lineamiento claro.

A pesar de lo anterior, es necesario identificar también la evidencia de una grave carencia conceptual, como lo refleja esta afirmación contenida en la Sentencia C-542 (Corte Constitucional, 1993): "El hombre, en síntesis, tiene dignidad porque es un fin en sí mismo y no puede ser considerado un medio en relación con fines ajenos a él" (s. p.). Así también, la Corte Constitucional (1996) en la Sentencia T-645, afirma: "La dignidad humana es un parámetro interpretativo que orienta nuestro sistema jurídico" (s. p.).
Teniendo en cuenta las variadas acepciones que ofrece la Corte sobre la dignidad humana, en este escrito se analiza este concepto con relación al atributo de la persona, lo cual podría servir como sustento teórico y jurídico al derecho de muerte digna. Para lograr este propósito, se hizo un estudio de los índices que la Corte Constitucional (1993) ha construido. Un ejemplo de ello es la Sentencia T-124, del 29 de marzo, la cual indica: "La dignidad (Artículo 1. Constitución Política) es un atributo de la persona, y, en cuanto tal, todos tienen derecho a que sean tratados conforme a esa dimensión específicamente humana" (s. p.).

Ahora bien, en el planteamiento de la dignidad humana como bien jurídico, la Corte Constitucional (1993) en la Sentencia C-565, del 7 de diciembre de 1993, plantea que "como se anotó con anterioridad, los bienes jurídicos atacados: la vida, la libertad, la dignidad, entre otros, juegan un papel determinante" (s. p.). De igual manera, la Corte Constitucional (1994) en la Sentencia C-213, de junio 9, propone que "son bienes jurídicos: la vida, la libertad y la dignidad [...] por cuanto, hacen relación a la especial protección que el Estado asigna a estos y a otros derechos fundamentales, teniendo en cuenta su importancia, según la jerarquía de valores" (s. p.). La Sentencia T-296 del 16 de junio de 1998 (Corte Constitucional) es aún más contundente: "Esto significa que la dignidad humana, como presupuesto del sistema de derechos y garantías consagrados en la 
Constitución, tiene un valor absoluto no susceptible de ser limitado bajo ninguna circunstancia" (s. p.).

Pues bien, para cerrar estos puntos de referencia que sirven a la relación entre muerte digna y dignidad humana, conviene hacer mención, una vez más, a la Corte Constitucional, Sentencia C-239 del 20 de mayo de 1997, con ponencia del magistrado Carlos Gaviria Díaz, quien declara que:

[... el carácter central de la dignidad humana, sin duda alguna, apunta primariamente a garantizar la construcción y proyección del sujeto moral en pleno uso de sus facultades vitales y morales. Pero también, la dignidad es algo más que esto. No se agota en el sujeto autónomo, apela también a un concepto más amplio de humanidad que cubre su declinar hasta su último fin. La dignidad como valor objetivo acompaña a la persona, independientemente de sus vicisitudes. (s. p.)

Por tanto, solo el titular del derecho a la vida, invocando su propia dignidad, tiene derecho a elegir — en caso de enfrentarse lentamente a una muerte cruel siendo consciente de su propio deterioro físico - hasta cuándo su vida es deseable y compatible con su propia dignidad. Además, la Corte Constitucional (2006) ha dicho que:

[...] los derechos fundamentales, no obstante su consagración constitucional y su importancia, no son absolutos y, por tanto, necesariamente deben armonizarse entre sí y con los demás bienes y valores protegidos por la Carta pues; de lo contrario, ausente esa indispensable relativización, la convivencia social y la vida institucional no serían posibles. (Sentencia C-651, 9 de agosto de 2006)

La vida humana como tal encuentra su límite en las decisiones de los individuos, pues a ellos atañe de manera indefectible y, por esto, si consideran que la vida debe terminar en el ejercicio de su libertad, el Estado no podrá oponerse a ello y tendrá que habilitar el procedimiento para que un tercero entre a mediar en una opción legítima y definitiva. "Si la razón por la que generalmente se prohíbe matar es que la vida es la posesión más preciosa de las personas, entonces, esa razón debe ser cambiada, si la persona no quiere vivir más", dice la Sentencia C-578, de la Corte Constitucional de 1995.

La Corte Constitucional (2014) mediante la Sentencia T-970 del 15 de diciembre de 2014 dictó pautas para hacer efectivo el derecho fundamental a una muerte digna. Para ello, recogió los fundamentos de la Sentencia C-239, de 1997, que despenalizó el homicidio por piedad y reiteró que la eutanasia puede ser practicada por profesionales de la salud, una vez verificada la voluntad del enfermo terminal. En el fallo instó al Ministerio de Salud y Protección Social para que emitiera una directriz y dispusiera lo necesario, de tal forma que se hiciera efectiva la conformación de un comité 
interdisciplinario que se encargara de aprobar el procedimiento.

Así pues, se puede interpretar que para la Corte Constitucional la eutanasia es tan solo un procedimiento para proteger el derecho a morir de forma digna, derecho que estaba ya protegido en la Sentencia C-239, de 1997, elevado a la categoría de derecho fundamental. Con esto fue posible, y también obligatorio, que en tanto se pretendió salvaguardar otros derechos como el desarrollo de la personalidad y la autonomía, se limitó el derecho a la vida. En el caso de las personas que padecen una enfermedad terminal — declaró la Corte— el deber de proteger la vida "cede ante su autonomía individual".

Entre los argumentos de la Sentencia T-970, de 2014, se destaca la posición de la Corte, al declarar que el requisito de que la enfermedad cause intensos sufrimientos al paciente no debe limitarse a un criterio médico, pues esto chocaría "con la idea misma de autonomía y libertad de las personas". Así, "será la voluntad del paciente la que determine, que tan indigno es el sufrimiento causado" (s. p.). De igual manera, la Corte establece que el consentimiento informado puede ser sustituido "cuando la persona que sufre de una enfermedad terminal se encuentra en imposibilidad fáctica para manifestar su consentimiento" (s. p.). En esos casos y con el propósito de no prolongar su sufrimiento, "la familia podrá sustituir su consentimiento".
La misma sentencia se refiere también a la objeción de conciencia, pues la Corte Constitucional deja sentado que "las convicciones personales que eventualmente se puedan oponer al cumplimiento de este deber, no pueden constituirse en obstáculo para la plena vigencia de los derechos fundamentales del paciente" (s. p.).

Así, en palabras de la Corte Constitucional y según la Sentencia T-970 de 2014 , el procedimiento para implementar la eutanasia sería como sigue:

[...] cuando se constate que la persona padece de una enfermedad terminal que le causa dolores intensos, la persona tendrá derecho a manifestar su deseo de morir. Esa voluntad será recibida por el médico, quién convocará al comité científico interdisciplinario para que comience su actividad. Una vez sea expresada la intención de morir, garantizando lo inequívoco del consentimiento, el médico o el comité deberá, en un plazo razonable (criterio de celeridad) que no podrá ser superior a diez (10) días calendario, preguntar al paciente si su intención aún continúa en pie. En caso de que así sea, el procedimiento será programado en el menor tiempo posible, que no podrá ser superior a lo que el paciente indique o máximo quince (15) días después de reiterada su decisión. En cualquier momento el enfermo podrá desistir de su decisión y con ello, activar otras prácticas médicas como los cuidados paliativos. (s. p.) 
Por todo lo anterior, la Sentencia T-970 de 2014 postula a Colombia como un Estado liberal y garantista con respecto a la eutanasia, la cual no solo estaría permitida por este pronunciamiento, sino que además sería obligatoria, teniendo en cuenta determinados supuestos. Lo anterior está en consonancia con las características tan especiales e individuales que manifiestan las personas en el final de la vida. Con esto se corre el riesgo de impedir la vivencia profunda del estado natural de la vida, del cual hacen parte la enfermedad y el deterioro físico normal de todo ser humano.

Teniendo en cuenta todo lo dicho en este escrito sobre la dignidad humana y muerte digna como derecho fundamental, es necesario hacer las siguientes consideraciones: estas son las circunstancias de modo y lugar mediante las cuales la muerte se produce y no la muerte en sí — como fenómeno natural al cual todos nos enfrentaremos-, de las cuales devienen los conflictos morales y jurídicos, con la pretendida relación entre los conceptos de muerte, derecho y dignidad.

Eutanasia, homicidio por piedad u homicidio eutanásico, son los términos que hacen parte de la Sentencia C-239 del 29 de mayo de 1997, al referirse del mismo modo sobre el homicidio por piedad y la eutanasia activa. Sin embargo, la Corte Constitucional hace la salvedad de que no todo homicidio por piedad es eutanasia. Con esto se crea una ambigüedad terminológica y conceptual en el texto de la nombrada sentencia.

Por otro lado, en la misma sentencia citada anteriormente, la Corte hace una homologación conceptual entre el derecho a vivir de forma digna y el derecho a morir de la misma manera. Aunque la Constitución no contempla expresamente ese derecho, para los Magistrados que votaron a favor del sentido del fallo de la Sentencia existe suficiente fundamento constitucional para afirmarlo. Vivir y morir son dos acciones de inconmensurable sentido axiológico. En la primera, no existe concurso de la voluntad individual para su aceptación, y en la segunda se puede acelerar su advenimiento antes de su presencia natural en el tiempo, como una decisión libre e individual. Esto demuestra un desequilibrio entre los dos conceptos; sin embargo, la Corte los homologa y los propone en la misma proporción lingüística e interpretativa.

El concepto de muerte digna es contrario al de humanización final de la existencia. No se trata pues de adelantar la muerte por medio de la eutanasia o postergarla con el "encarnizamiento terapéutico". Humanizar el final de la vida de un paciente terminal consiste en proveerle atención médica, cuidados paliativos, evitarle procedimientos abusivos, mitigar su dolor y, si es creyente, ofrecerle la posibilidad de la asistencia espiritual. Las opciones de muerte digna o de humanización de la existencia se deben 
presentar al paciente terminal y a su familia, antes de tomar una decisión tan trascendental como la de un suicidio asistido.

El derecho a morir con dignidad corresponde entonces, según la Corte Constitucional, al paciente terminal que sufre intensos dolores y que solicita que le "ayuden a morir", pues su situación es contraria a la idea que tiene de "vivir con dignidad". Con esto, en el plano conceptual quedarían en la misma altura semántica el derecho a morir con dignidad y la eutanasia, lo que equivale a una confusión que se hace extensiva al lenguaje común de los ciudadanos.

\section{El caso de Ovidio González}

Ovidio González, un hombre de 79 años, quien padecía cáncer de boca, perdió parte de su rostro y decidió invocar la eutanasia en 2015. Consideró que su estado era de indignidad y su vida, según él, dejó de ser un bien. La legalidad de su pretensión estaba identificada en el contexto de la despenalización de la muerte asistida, de la Corte Constitucional, Sentencia C-239 de 1997, y que el Ministerio de Salud y Protección Social reglamentó su forma en marzo de 2015. Los médicos de la Clínica de Oncólogos de Pereira aplazaron el procedimiento de eutanasia en el caso de Ovidio, por considerar que no se trataba de una "enfermedad terminal", requisito necesario para solicitarla, según el Ministerio de Salud y Protección Social (2015)
Resolución 1216. Por esta situación, el drama de don Ovidio se hizo público en todo el país, al demostrar enormes complejidades, pues se trataba de la invocación de uno de los derechos que suscita más resistencia y oposición: el derecho a morir.

Cuando el caso se hizo público, los hijos de Ovidio expresaron ante los medios de comunicación que la solicitud de su padre era legal y legítima, y al invocar apartes de la Sentencia de la Corte Constitucional, C-239 de 1997, plantearon "que el derecho a la vida no puede reducirse a una mera subsistencia. Nada tan cruel como obligar a una persona a sobrevivir en medio de padecimientos oprobiosos, en nombre de creencias ajenas". La Corte estimó que los colombianos tenían el derecho de "decidir hasta cuándo la vida es deseable y compatible con la dignidad humana" (s. p.).

La petición de Ovidio y sus familiares se hizo válida, en el contexto de la exigencia de la Corte Constitucional al Ministerio de Salud y Protección Social, para que expidiera un decreto que obligó a los hospitales del país a reglamentar un comité que revisara las solicitudes de eutanasia, asegurándose antes que el paciente recibiera los cuidados paliativos necesarios y se determinara el estado terminal de su enfermedad, y se resolvía su situación en máximo diez días calendario.

La citada Resolución No 1216 estableció que podía aplicar a este procedimiento: 
[...] todo aquel que es portador de una enfermedad o condición patológica grave, que haya sido diagnosticada en forma precisa por un médico experto, que demuestre un carácter progresivo e irreversible, con pronóstico fatal próximo o en plazo relativamente breve, que no sea susceptible de un tratamiento curativo y de eficacia comprobada, que permita modificar el pronóstico de muerte próxima; o cuando los recursos terapéuticos utilizados con fines curativos han dejado de ser eficaces.

El caso de Ovidio polarizó el debate por la muerte digna en Colombia, pues el derecho a morir toca la identidad de la condición humana. La pretensión de Ovidio se hizo efectiva, al ser la primera vez que se hace dentro del sistema de salud colombiano. Con el cumplimiento de la petición de Ovidio, la legislación colombiana aseguró que la libertad y la autonomía de los seres humanos son la principal fuente de dignidad. El Estado respetó las decisiones individuales, expresando las opiniones de quienes aseguran que la prolongación de la vida a toda costa por métodos artificiales es una visión equivocada de los fines de la medicina, pues mantener con vida a alguien en contra de su voluntad, es una indignidad.

Por otro lado, el caso de Ovidio suscita serios interrogantes, en especial para los jóvenes en formación, pues demuestra cambios súbitos e irreversibles en el imaginario social, porque deja en vilo los códigos de la tradición médica y desestimula la investigación. Además, posiciona de manera asimétrica a los jóvenes, a los saludables y los productivos, sobre los ancianos, los débiles, los enfermos, los deformes y los dementes, y los ubica en un plano, al parecer, como "inservibles" para un sistema de producción y que, por tanto, puede disponer de sus vidas, lo que cosifica la axiología que reivindica su dignidad. Se invierte el verdadero sentido de la justicia social y la adherencia a una sociedad democrática y altruista. Deja a disposición de los balances económicos la vida de los frágiles, al permitir con ello que los comités de ética médica corrompan sus ideales, apoyados por el secularismo, y pretendan buscar el mejor bien, relativizando su compromiso con la defensa de la vida y el respeto por la dignidad humana.

\section{Conclusiones}

La deliberación sobre la eutanasia y el suicidio asistido hace parte de un debate amplio, pues se debe promover más para que los ciudadanos puedan tener y mantener una posición libre y responsable a lo largo de toda su existencia. El aspecto central de todo esto es la autodeterminación de poder elegir. Por eso, en una sociedad plural como la nuestra, el "testamento vital" reviste una importancia capital; dejar por escrito su consentimiento, incluso sin estar enfermo, qué hacer en un estado terminal de una posible enfermedad, una pérdida de conciencia o un accidente acérrimo. La 
libertad es un principio universal que debemos defender. El conocimiento es una condición para ejercer la libertad, con una actitud sincera y crítica, superando los dogmatismos.

El debate sobre la eutanasia suscita controversias apasionadas, porque pone en juego valores y convicciones personales, sociales, legales, morales y religiosas. También porque la toma de decisiones sobre la vida y la muerte es una cuestión muy álgida, especialmente cuando entra a mediar y a decidir el bioderecho. Este tema es controvertido porque desde distintas aristas del derecho, varios magistrados con posiciones contrarias ante la eutanasia se refieren al mismo caso de muerte médicamente asistida y de manera sorprendente interpretan jurídicamente - amparados en la legislación colombiana_ los mismos hechos de forma distinta, con lo cual se polariza la opinión de la sociedad.

El principio ético de autonomía es sobre el cual se fundamenta y se soporta la consideración sobre la eutanasia. En un estado social de derecho como lo es Colombia, se debe aceptar que existen opciones diferentes para vivir y morir, y que se debe respetar la voluntad de quien está soportando una terrible enfermedad.

\section{Referencias}

Atienza, M. (1999). Juridificar la bioética. En R. Vásquez (Comp.), Bioética y derecho. Fundamentos y problemas actuales (2da. Ed., pp. 64-91). México, D. F: Fondo de Cultura Económica.
Colombia, Corte Constitucional (29 de marzo de 1993). "Sentencia T-124/93" [M. P. Vladimiro Naranjo Mesa]. Recuperado de http://www.corteconstitucional.gov. co/relatoria/1993/T-124-93.htm

Colombia, Corte Constitucional (24 de noviembre de 1993). "Sentencia C-542/93" [M. P. Jorge Arango Mejía]. Recuperado de http://www.corteconstitucional.gov. co/relatoria/1993/c-542-93.htm

Colombia, Corte Constitucional (7 de diciembre de 1993). "Sentencia C-565/93" [M. S. Hernando Herrera Vergara]. Recuperado de http://www.corteconstitucional.gov.co/relatoria/1993/C-565-93.htm

Colombia, Corte Constitucional (28 de abril de 1994). "Sentencia C-213/94" [M. P. Jorge Arango Mejía]. Recuperado de http://www.corteconstitucional.gov.co/ relatoria/1994/C-213-94.htm

Colombia, Corte Constitucional (15 de diciembre de 1994). "Sentencia No. C-224/94" [M. P. Jorge Arango Mejía]. Recuperado de http://www. corteconstitucional.gov.co/relatoria/1994/C-224-94.htm

Colombia, Corte Constitucional (4 de diciembre de 1995). "Sentencia C-578/95" [M. P. Eduardo Cifuentes Muñoz]. Recuperado de http://www.corteconstitucional.gov.co/relatoria/1995/c-578-95.htm

Colombia, Corte Constitucional (26 de noviembre de 1996). "Sentencia T-645/96" [M. P Alejandro Martínez Caballero]. Recuperado de http://www.corteconstitucional.gov.co/relatoria/1996/T-645-96. htm

Colombia, Corte Constitucional (20 de mayo de 1997). "Sentencia No C-239/97" [M. P. Eduardo Cifuentes 
Muñoz, Jorge Arango Mejía, Carlos Gaviria Díaz, José Gregorio Hernández Galindo, Hernando Herrera Vergara, Alejandro Martínez Caballero, Fabio Monrón Díaz y Vladimiro Naranjo Mesa]. Recuperado de http://www. corteconstitucional.gov.co/relatoria/1997/c-239-97.htm

Colombia, Corte Constitucional (16 de junio de 1998). "Sentencia T-296/98" [M. P. Alejandro Martínez Caballero]. Recuperado de http://www.corteconstitucional.gov.co/relatoria/1998/t-296-98. htm

Colombia, Corte Constitucional (9 de agosto de 2006). "Sentencia C-651/06" [M. P Clara Inés Vargas Hernández]. Recuperado de http://www.corteconstitucional.gov.co/relatoria/2006/C-651-06. htm

Colombia, Corte Constitucional (15 de diciembre de 2014). "Sentencia T-970/14" [M. P. Luis Ernesto Vargas Silva]. Recuperado de http://www. corteconstitucional.gov.co/relatoria/2014/t-970-14.htm

Gracia, D. (1990). Historia de la eutanasia. En N. Albesa y J. Gafo (Eds.), La eutanasia y el arte de morir (pp.13-32). Madrid: Universidad Pontificia Comillas.

Have, H.T. (Octubre, 1996). La eutanasia: la experiencia holandesa. En Morir con dignidad: dilemas éticos en el final de la vida. Actas de la Jornada organizada por la Fundación de Ciencias de la Salud. Doce Calles Aranjuez.

Herránz Rodríguez, G. (1990). Eutanasia o medicina. Cuadernos de Bioética, 4(1), 21-23.
Humphry, D. y Wickett, A. (1990). The right to die. Oregon: Helmock Society.

Look, S, Last, J.M. y Dunea, J. (2001). The Oxford illustrated companion to medicine. Oxford: Oxford University Press.

Marx, F (1977). Medical euthanasia. En S. J, Reiser, A.J, Dyck y W.J. Curran (Eds). Ethics in medicine: historical perspectives and contemporary concerns (pp. 84-86). Cambridge: MIT Press.

Ministerio de Salud y Protección Social (20 de abril de 2015). "Resolución No 1216/15”. Recuperado de https://www. minsalud.gov.co/Normatividad_Nuevo/Resoluci\%C3\%B3n\%201216\%20 de\%202015.pdf

Nombela, C., López, F., Serrano Ruiz-Calderón, J.M., Postigo, E. et al. (s. f). La eutanasia: perspectiva ética, jurídica y médica. Recuperado el 15 de mayo de 2016, de http://eprints.ucm.es/11693/1/ La_Eutanasia_perspectiva_etica_juridica_y_medica.pdf

Potter, van R. (s.f.). La bioética global. Recuperado el 15 de mayo de 2015, de http://ntic.educacion.es/w3/tematicas/ genetica/2001_10/2001_10_01.html

Redacción Política (4 de noviembre de 2014). Eutanasia en Colombia. Reviven proyecto para reglamentar eutanasia en Colombia. El Espectador. Recuperado el 15 de mayo de 2016, de http:// www.elespectador.com/noticias/politica/ reviven-proyecto-reglamentar-eutanasia-colombia-articulo-525818

Reich, W.T (1995). La euthanasia. Encyclopedia of Bioethics, 1 .

Richman, J. (1993). Euthanasia meanings. En R. Kastenbaum y B. Kastenbaum 
(Comps.), Encyclopedia of Death (pp. 114-119). Nueva York: Avon Books.

Salud (2 de julio de 2015). Aprueban practicar la eutanasia a Ovidio, padre del caricaturista "Matador". Esta será la primera eutanasia legal que se realiza en Colombia. El Espectador. Recuperado el 15 de mayo de 2015, de http:// www.elespectador.com/noticias/salud/ aprueban-practicar-eutanasia-ovidio-padre-del-caricatur-articulo-569777

The World Medical Association (2016). About the wmA. Recuperado el 15 de mayo de 2016, de http://www.wma.net/ en/60about/index.html.pdf?print-media-type\&footer-right=[page]/[toPage 